\title{
Determinants of Household's Healthcare Payment in Nepal: Evidence from Living Standard Survey III Data.
} Arjun Kumar Thapa ${ }^{1} \&$ Sonia Singla ${ }^{2}$

${ }^{1} \mathrm{PhD}$ Scholar, Mewar University, Rajasthan, India

${ }^{2}$ Research Supervisor, Assistant Professor, Department of Economics, Mewar University, Rajasthan, India

\section{Corresponding Author}

Arjun Kumar Thapa

Email: yogirajarjun@gmail.com

\begin{abstract}
Healthcare financing has always remained an important development issue for Government of Nepal to ensure equity and availability of basic health care services for all but the largest portion of health financing is met by out of pocket payment (OOP), a private financing source of households. So this study aims to assess the situation of private healthcare financing and analyze the factors associated with it. A cross sectional descriptive cum analytical study was designed based on living standard survey data of CBS (2012), Nepal. It is a rich and country wide representative data comprising 5988 households. The study applied logistic regression to analyze the determinants of out of pocket payment. The major findings of the study shows a particular household's mean healthcare cost was NRs. 1119 for acute illness and cost of medicine occupied the major portion of the cost. The mean OOP healthcare cost is higher for urban residents, mountain dwellers, and households belonging to province 3 and people belonging to highest wealth quintiles. The odds of household facing OOP payment increases for male headed households, larger households and households belonging to province number 2. Conversely, odds of household facing OOP decreases for households residing in urban and province number 4. The study concludes that out of pocket payment is an important source of private healthcare financing source. So there is a need to effectively implement the demand side financing programs and health insurance scheme to protect households from financial burden.
\end{abstract}

\section{KEYWORDS}

Healthcare Expenditure, Household, Out-of-pocket Payment

\section{INTRODUCTION}

Ever since First and second Long Term Health policies were implemented during 1990's, the government of Nepal (GoN)was committed to expand the coverage of basic health care services across the country targeting the ultra-poor, poor, disadvantaged and marginal sections of people (MoHP, 2010).Out-of-pocket payments (OOP), which refer to payments made by households at the point of receiving health services like hospital bills, doctors' consultation fees and purchases 
of medication (Van Minh, 2013), is big hurdle towards universal health coverage (UHC). Despite fair increase in coverage by public health facilities, and awareness towards modern medicines the private payment made by individuals or households from their own pocket or out of pocket (OOP) spending has been on rise, impinging the poorer sections of people. OOP health expenditure for any household or individual is devastating if it exceeds her/his ability to pay (ATP). According to Jack (1999) if an individual falls sick and wants to purchase health care services, then he has to reallocate his expenditure among health care commodity and other market commodities in order to increase purchase of every additional healthcare service units. Now he may have to reduce his general consumption of other commodities. In many instances health care payment (OOP) may lead to impoverishment. Impoverishment occurs when people or households fall below the poverty line because of healthcare expenditure. Based on the study of 11 low to middle income Asian countries van Doorlaer et al. (2006b) estimated that poverty rates (US\$1 per day) would increase by 2.7 percentage points (or 78 million people) if household resources were assessed after accounting for health expenditures. Ghosh (2011), while measuring catastrophic health care expenditure incidence (OOP $>10$ percent consumption) of India found that $4.4 \%$ of total population in India fell below poverty line because of OOP payment during 1993/94 to 2004/05 period. In order to ascertain universal healthcare coverage and financial risk protection the GoN implemented Free Health Care Program (FHCP), promulgating basic healthcare as component of human rights in 2009 (Adhikari, 2013). The FHCP was targeted to ensure right to basic health care services to all Nepalese citizens; to increase coverage and utilization of health services by poor, disadvantaged and targeted groups (RTI, 2010). Most of the health policies and programs, especially the demand side financed programs aimed to reduce OOP and impoverishment. Even Nepal Health Sector Plan II (NHSP-2)'s vision was also aimed to improve the health and nutritional status of the Nepalese population, especially for the poor and excluded as well as to contribute to poverty reduction by providing equal opportunity for all to receive high-quality and affordable health care services. (MoHP, 2010). But most of the studies show that households in low-income countries spend a significant portion of their resources (OOP) on remedial health care. For instance a study of public primary facilities, in seven districts across Nepal shows more than half of outpatient visitors pay from their pocket (OOP) for healthcare services where diagnosis and sufficient list of medicines are free (Thapa et al., 2016).It seems that mere provision of healthcare coverage, availability and freeing some medicines has not been able to cap up OOP spending especially by poorer, disadvantaged and marginalized section of the society leading to catastrophic health care payment causing impoverishment or tendency of households falling under the trap of poverty line. So this study intends to describe the association of OOP payment with household characteristics, magnitude and distribution of OOP payments; and the incidence of poverty that occurs because of OOP payments in Nepal.

\section{DATA\&METHOD}


This study is a cross-sectional analytical design, aimed to describe associational relationship between OOP and socio-demographic characteristics of households who are seeking health care service, and level of impoverishment due to OOP expenditure. The source of data is based on secondary collected by Central Bureau of statistics (CBS, 2012), National Planning commission / Government of Nepal which is latest till date and a nationally representative data.NLSS III, anational household survey conducted by CBS follows the World Bank's Living Standards Measurement Survey (LSMS) methodology. The study depends on cross sectional data extracted on demographic, consumption and health sections of NLSS III which comprised 5988 households comprising around 28,000 individuals. But the population of interest for the study was only 5,518 individuals who reported being ill or injured within the last one month from the day of interview. The unit of analysis is household and individual. Cross tabs and multiple tables was used where comparison were required. For comparative study and causal relational studies chi square test was used as most of the attributes are of qualitative nature. It was analyzed using STATA package and MS Excel spread sheet.

\section{Measurement of OOP Payment}

Ensuring financial protection is an important issue in health policy. There are three ways to measure financial protection: 1) out-of-pocket spending as a share of total health spending; 2) out-of-pocket spending as a share of household consumption by income class; 3) percentage of households driven into poverty by catastrophic medical expenses (OECD, World Bank, 2008). In this part the out of pocket (OOP) payment comprises of total reported spending on consultation, medicines and other medical costs plus the indirect health cost incurred. The table below shows the total health care expenditure spent by the individuals /households for seeking health services both in public and private institutions. The OOP payment data of two NLSS surveys (NLSS II, 2003/04 and NLSS III, 2010/11) are presented in the given table.

\section{Regression Model}

The probability of out of pocket (OOP) payment or not was calculated by the simple logistic regression equation as:

$$
\begin{aligned}
& \operatorname{pr}(y=1)=\frac{\exp \left(x_{j} \beta\right)}{1+\exp \left(x_{j} \beta\right)} \\
& Y=\alpha+\beta_{1} X_{1}+\beta_{2} X_{2} \ldots+\beta_{n} X_{n}
\end{aligned}
$$

Where, $\mathrm{y}$ is the presence of OOP payment on health expenditure. If the households incur health care expenditure then we consider $y=1$, otherwise $=0 . X j$ is a set of predetermined variables, $\beta$ a set of parameters to be estimated.

Where, $\beta_{1}, \beta_{2} \ldots \ldots \ldots \ldots \ldots \beta_{n}$ are coefficients to be determined and $X_{1} \ldots \ldots X_{n}$ are demographic, social, economic, morbidity variables

\section{RESULT \&ANALYSIS}


ISSN: 2362-1303 (Paper) | eISSN: 2362-1311 (Online)

JOURNAL OF ADVANCED ACADEMIC RESEARCH (JAAR)

Out of total 5,518 reported to be sick or ill in the last one month from the day of interview but around $30 \%$ of them did not seek any treatment in formal sector. The out of pocket expenditure is the private healthcare expenditure spent by the households or individuals for their seeking healthcare services. Over 60 percent of the total population seeking healthcare services faces out of pocket healthcare payment (Table 1).

The OOP payment comprises of consultation fees, medicines cost travel cost. The consultation fee and medicine costs are regarded as direct medical cost and travel cost is regarded as indirect medical cost (Table 1).

Table 1: Household's healthcare cost (OOP)

\begin{tabular}{|lcccc|}
\hline \multicolumn{4}{l}{ NLSS II } & \multicolumn{3}{l|}{ NLSS III } \\
\hline Variable & Mean cost & \% share of total & Mean cost & \% share of total \\
\hline consultation & 146 & 18.6 & 266 & 23.8 \\
\hline medicines & 574 & 73.4 & 758 & 67.7 \\
\hline travel cost & 62 & 7.9 & 95 & 8.5 \\
\hline total cost (OOP) & 782 & 100 & 1119 & 100.0 \\
\hline
\end{tabular}

Source: Self compilation from CBS (2012)

Medicines cost occupies the largest portion of total health care cost for both the periods i.e., $73.4 \%$ in $2003 / 04$ and $67.7 \%$ in $2010 / 11$. The cost on consultation fee has also increased from $18.6 \%$ in $2003 / 04$ to $23.8 \%$ in $2010 / 11$ which indicates health consumer visiting formal institutions for consulting regarding their ailments.

The share of OOP healthcare expenditure as percentage of consumption expenditure for households belonging to different quintiles group is presented below (Table 2).

Table 2: OOP as share of consumption expenditure of Household

\begin{tabular}{lcc}
\hline & OOP as \% of Consumption expenditure & OOP as \% of non-food expenditure \\
\hline Poorest Fifth & 5.65 & 20.45 \\
\hline 2nd poorest Fifth & 5.26 & 18.18 \\
\hline Median Fifth & 4.45 & 12.86 \\
\hline 2nd richest Fifth & 3.86 & 9.55 \\
\hline Richest Fifth & 1.96 & 3.22 \\
\hline Total & 3.33 & 7.07
\end{tabular}

Source: Self compilation from CBS (2012)

As per the given table above, the average percentage of OOP's share in total consumption is 3.33 percent and non-food consumption is $7.07 \%$. The OOP as percentage of consumption expenditure for households belonging to lowest quintiles is significantly high $(5.65 \%)$ while that of non-food expenditure is $20.45 \%$. Conversely, a lower percentage of consumption expenditure is spent by the richest fifth. 


\section{Mean health care cost (OOP) by Place of residence, belt and wealth quintile}

Nepal is small but a diverse country with plains to difficult topography, recent provincial divisions and wealth quintiles. Due to difficult topography and remoteness, all round the year supply of medicines and availability of health human resource is not possible in rural areas. The figure below shows that the mean health care cost for households residing in urban areas is NRs. 1461 while it is NRs 982 for rural dwellers. The rugged topography and scattered settlement in rural hill and mountain are barriers for effective coverage of health care facilities by the government. The availability of medicines and health personnel's in government healthcare institutions is difficult so people might have to travel long distances to nearest urban pocket areas. The lower cost for rural residents might be due to unavailability of healthcare facilities (Figure 1).

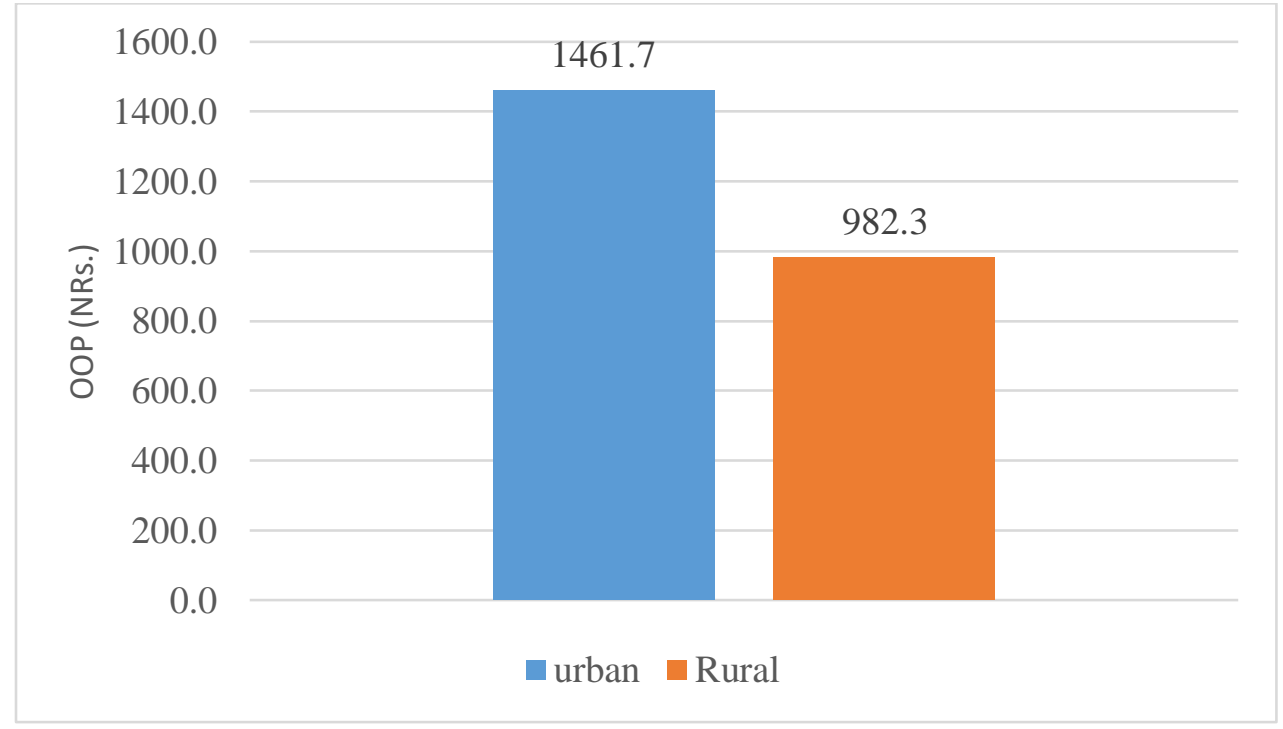

Figure 1: OOP Payment by Place of Residence

Source: CBS, 2012

Low OOP payment in rural areas indicates two situations: one unavailability of health facilities and secondly low health seeking behavior or abstinence of health utilization. 


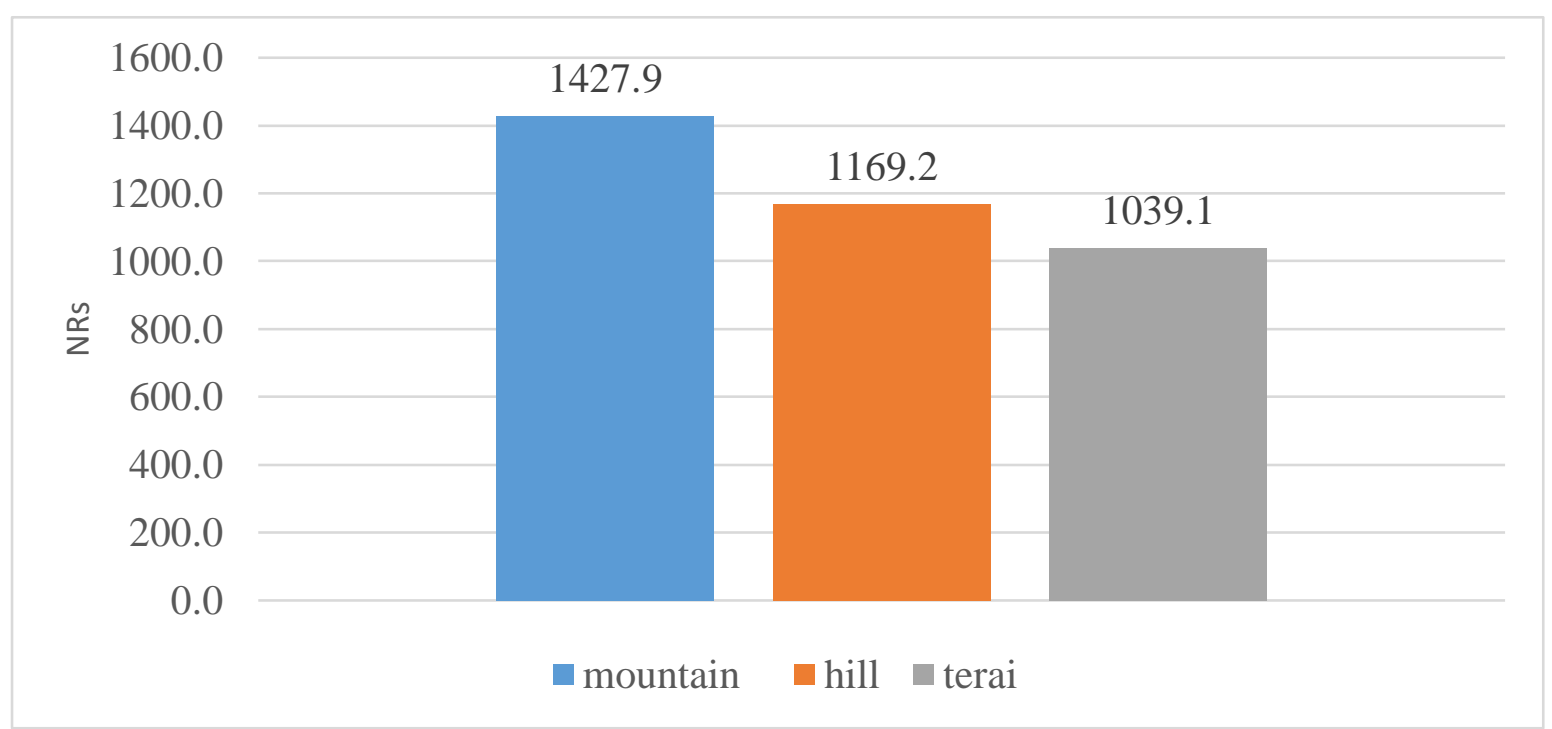

Figure 2: OOP (NRs) by Ecological Belt

Source: CBS, 2012.

As per the ecology Nepal is divided into three belts: Mountain - Furthest north the Himalayan region; Hill - lying between plain and Moutain region; Terai - the southern plain. Among the three belts, OOP payment is highest (NRs. 1427) among the households residing in Mountain belt (Figure 2).

The transportation is difficult in Mountain belt. The cost of transportation and other indirect cost might lead to higher cost. Apart from that scanty population also poses challenges for government effort in increasing the health care coverage.

After implementation of new constitution, Nepal has become federal state and the country is divided into seven provinces. These provinces can be categorized again by their level of development. For instance, the development indicators of province 7, 6 and 2 are very low as they belong to Far west, Mid-west development region, and eastern Terai whose development indicators are low (Figure 3). 
ISSN: 2362-1303 (Paper) | eISSN: 2362-1311 (Online)

JOURNAL OF ADVANCED ACADEMIC RESEARCH (JAAR)

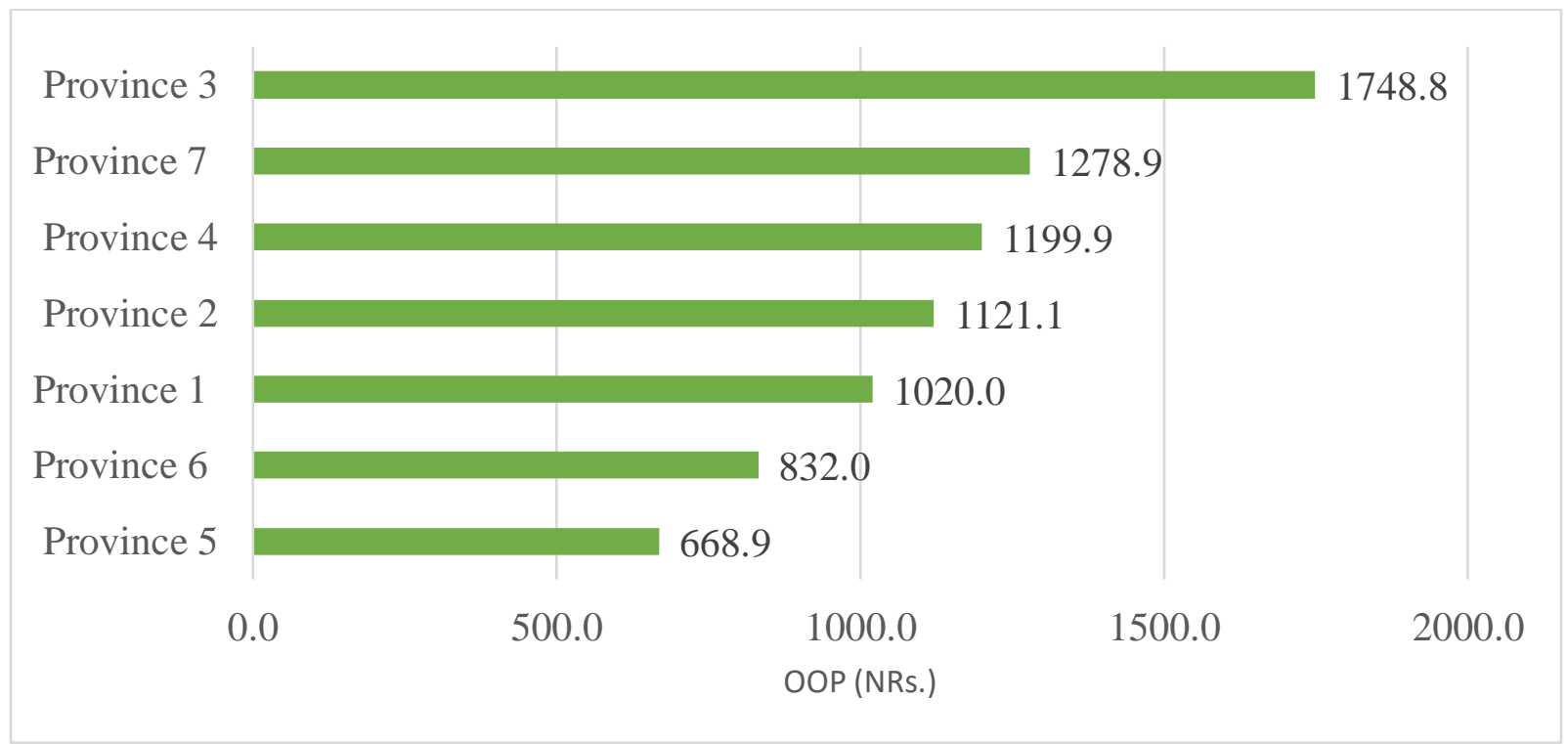

Figure 3: OOP Expenditure by Province

Source: CBS, 2012

Among the newly formed provinces, health care cost is very costliest (NRs. 1748.8) for people belonging to province no. 3 , and then followed by province7, $4 \& 2$. Province 3 , where the capital Kathmandu lies, is the highly populous province. The development indicators are good and country's public and private health facilities are concentrated here. The higher OOP in province 7 might be due to higher indirect medical cost like transportation. But it is surprising that in province no. 5 and 6 are lowest, whose development indicators are very low, the OOP payment is lower. One reason might be no proper coverage and utilization of health services and other might be due to low health behavior towards modern medicines.

In order to assess OOP payment and economic status, the households are grouped into quintiles. It is understood that OOP payment should be high for higher quintile group and vice versa. From the given figure we note that lowest quintile households paying fairly higher than those belonging to $2^{\text {nd }}, 3^{\text {rd }}$ and second highest quintile. It indicates that households lying in low quintiles are mostly rural, remote and Terai residents. 
ISSN: 2362-1303 (Paper) | eISSN: 2362-1311 (Online)

JOURNAL OF ADVANCED ACADEMIC RESEARCH (JAAR)

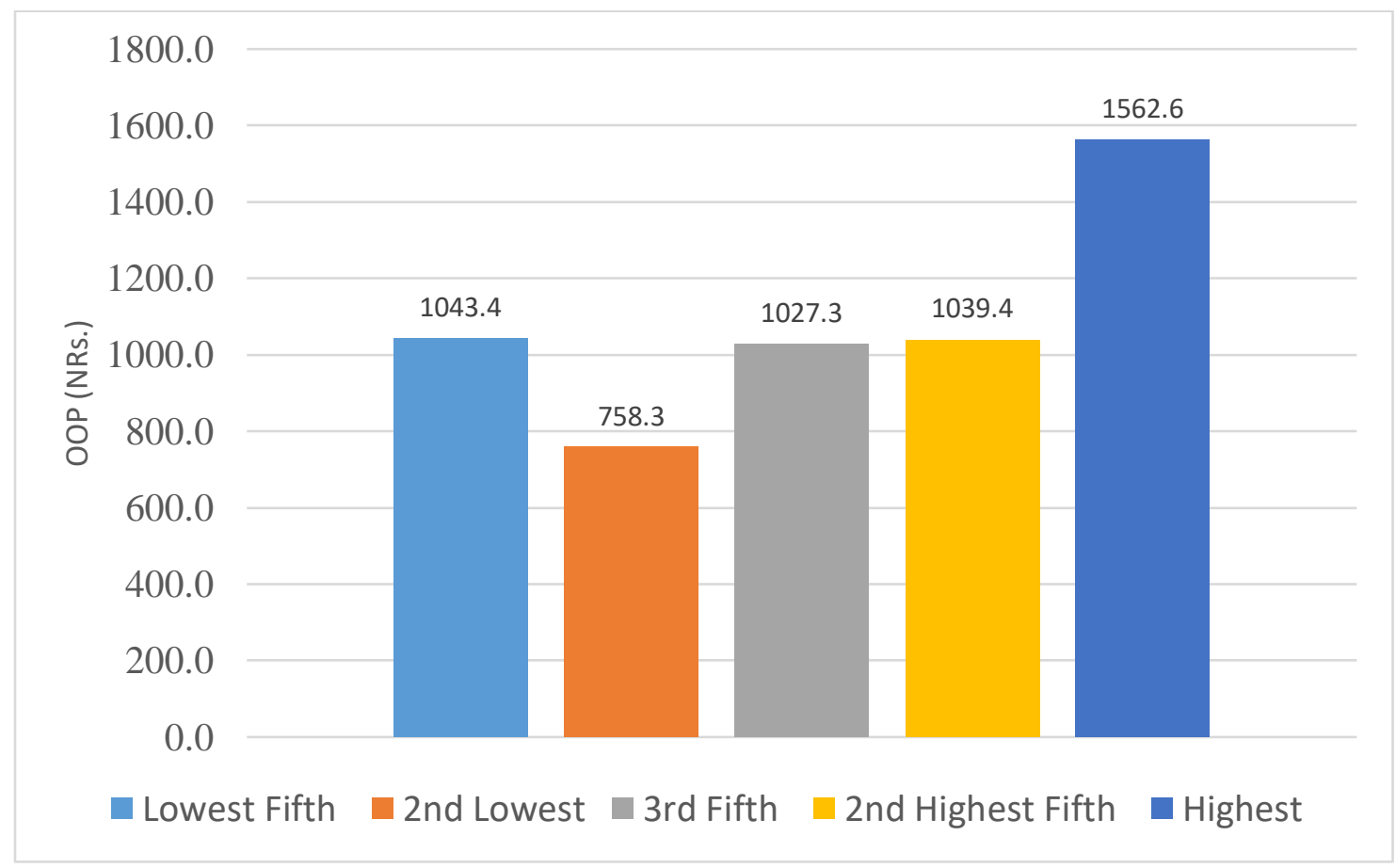

Figure 4: OOP (NRs) by Income Quintile

Source: CBS, 2012

The highest $5^{\text {th }}$ are paying highest OOP (NRs. 1562) is theoretically plausible as the richer can seek treatment in private facilities (Figure 4).

\section{Regression Result}

To determine what factors are responsible for a households being facing catastrophic payment a regression was run. The dependent variable is out of pocket (OOP) payment or not and the independent variables are household characteristics: sex of the household head, marital status of the household head, literacy of head, family size; the residential and location characters : urban or rural residence, province; and economic and health characters: income quintile and chronic ill or not. The adjusted R-square is $9 \%$ which means around 7 percent of the variation in dependent variable is explained by independent variables. But R2 value do not play significant role in explain behavior of logistic regressions. The ROC test shows a goodness of fit for the logistic regression (Annex 1).

Sex of head, place of residence, province economic status is statistically significant (Table 3). But other variables like household size and chronic ill or not are weakly significant. The odds that sex of head being male is highly likely to face OOP health care payment. It means if the household head is male, then household is likely to face OOP payment by 1.3 times (at 95\% CI: 1.093 to 1.541 ) with reference to female headed household head. 
ISSN: 2362-1303 (Paper) | eISSN: 2362-1311 (Online)

JOURNAL OF ADVANCED ACADEMIC RESEARCH (JAAR)

June 2019

Table 3: Regression Result

\begin{tabular}{|c|c|c|c|}
\hline Variables & Odds Ratio & Std. Err. & [95\% Conf.Interval] \\
\hline Head sex*** (rf female) & 1.298415 & 0.113829 & 1.093428 to 1.54183 \\
\hline Maritalstatus head (rf other) & 1.11885 & 0.116901 & 0.911665 to 1.373119 \\
\hline Householdsize* & 1.039551 & 0.020628 & 0.999896 to 1.080778 \\
\hline Headliteracy (rf illiterate) & 1.102764 & 0.086112 & 0.946268 to 1.28514 \\
\hline Urbanrural*** (rf urban) & 0.5139776 & 0.050591 & 0.423799 to 0.623345 \\
\hline \multicolumn{2}{|l|}{ Province(rf. Province 1) } & & \\
\hline Province 1 & 0.9726965 & 0.155384 & 0.711216 to 1.330312 \\
\hline province $2 * * *$ & 8.130055 & 1.835725 & 5.222717 to 12.65583 \\
\hline province 3 & 0.832369 & 0.135091 & 0.605575 to 1.1441 \\
\hline province $4 * *$ & 0.6610748 & 0.113835 & 0.471712 to 0.926455 \\
\hline province 5 & 1.021979 & 0.160832 & 0.750734 to 1.391227 \\
\hline province 6 & 1.166168 & 0.239414 & 0.779848 to 1.743862 \\
\hline \multicolumn{4}{|l|}{ Quintile rf. Highest } \\
\hline Lowest fifth*** & 0.6405046 & 0.087378 & 0.490232 to 0.836841 \\
\hline 2nd lowest** & 0.7321215 & 0.095604 & 0.5668 to 0.945664 \\
\hline 3rd fifth & 0.8431727 & 0.107064 & 0.657405 to 1.081434 \\
\hline 2nd highest fifth*** & 0.7463532 & 0.083478 & 0.599431 to 0.929287 \\
\hline Chronic_ill* (rf. Chronic) & 0.8496017 & 0.078881 & 0.70825 to 1.019165 \\
\hline _cons & 4.908303 & 1.063231 & 3.210296 to 7.504429 \\
\hline \multicolumn{4}{|c|}{$\begin{array}{l}\text { Adjust } \mathrm{R} 2=0.07 ; \text { No. observations }=5263, \text { LR chi } 2(16)=374.52, \text { prob }>\text { chi } 2=0.000, \\
\text { loglikelihood }=0.0702\end{array}$} \\
\hline \multicolumn{4}{|c|}{$\begin{array}{l}\text { @ - Nawalparasi district is totally lumped into province 4; - Rukum district is totally lumped in } \\
\text { province } 6\end{array}$} \\
\hline
\end{tabular}

Source: Self-compilation from CBS, 2012

But the odds of household facing OOP payment are less likely in comparison to households residing in rural areas. The odds of household facing OOP decreases by 0.5 times in comparison to households residing in urban areas; is statistically significant. But in case of provinces, the odds of household facing out of pocket payment significantly increases if households live in province 2 . The odds of household facing OOP increases by 8 times if it is residing in province 2 with reference to province 7. Province 2 is Terai of Nepal. But the odds of household facing OOP payment decrease if it belongs to province 4. It is surprising that households lying at lowest quintiles (bottom first and second) are less likely to face OOP payment with reference to households belonging to highest quintiles. 


\section{DISCUSSION}

As per this study medicines cost occupy the largest portion of total private health care cost (OOP) which resembles to findings of Ghosh (2010) who also estimated spending on drugs as in 15 Indian states. Country wide OOP payment of Nepal as percentage of total consumption expenditure is $3.33 \%$ is also similar to study of poorer Indian states of Assam and Bihar (3.8\% and $2 \%$ respectively)even though India's overall OOP payment as percent of consumption is around 5 percent (Garg\& Karan, 2009). But current findings are in contrast to another similar study of Nepal (Gupta \& Chowdhury, 2014), which may be due to methodological differences.

This study shows that the share of OOP as \% of average consumption for poorest quintile and second poorest quintile is highest (around 5 percent) in comparison to richest fifth of the population (around 2 percent). It coincides with the study done on implications of Free Health Care Program of Nepal that concluded its unintended effect on marginal and targeted population whose OOP payment tendency and catastrophic payment did not improve (Adhikari, 2013).But some other studies conducted in slums of Hyderabad, India and in Western Kenyafound much higher OOP as \% of household expenditure i.e. 10\% and 8\% respectively (Banerjee et al., 2009). Further the OOP as \% of non-food expenditure is highest (around 20\%) for poorest fifth. A study done in Bihar and Assam, the poorer Indian states also show low OOP percent share of consumption which was due to low utilization of facilities (Thapa\&Adhikari, 2016). The above arguments are also supported by findings another study on Nepal's healthcare system in 2004which infers that distribution of financial protection and access to health in rural and remote areas did not improve much (Adhikari\&Maskay, 2004). The households headed by males, urban residents, residing in Mountain region and households belonging to province no. 3 are paying higher OOP payment than their respective categories. The regression result shows sex of head, place of residence, and economic status as important determinants of OOP payments among Nepalese households.

\section{CONCLUSIONS}

Out of pocket payment is an important source of private financing for people in Nepal and expenditure on medicine is its major portion. The burden of OOP is high for households belonging to low income strata. A higher percentage of Households whose head are male, reside in rural areas, belong to province 2, and who belong to lowest and highest economic status determine family facing OOP. So there is a need to address lacunae in fair coverage and utilization of health services across the country along with impoverishment of commons.

\section{ACKNOWLEDGEMENTS}

I would like to acknowledge Dr. Shiva Raj Adhikari, Professor, Central Department of Economics, TribhuvanUniversty, for his valuable guidance and support.

\section{REFERENCES}

Adhikari, SR. \&Maskay, N.M.(2004).Health sector policy in the first decade of Nepal's 
ISSN: 2362-1303 (Paper) | eISSN: 2362-1311 (Online)

Multiparty democracy. Does clear enunciation of health priorities matter? ELSEVIER, Health Policy 68; 103-112.

Adhikari, SR.(2013). 'Choices of health care financing schemes for resource poor country: An analysis of Nepal's experiences'. Health 5 (2013) 1295-1302.

Adhikari S.R.(2013). An evaluation of Nepal's free health care scheme: evidence from a quasiexperimental design. In: Social Science Research Network.

Banerjee, A., Esther, Du. O, Glennerster, R., \&Kinnan, C. (2009). The Miracle of Microfinance? Evidence from a Randomized Evaluation,mimeo, MIT, 2009.

Garg C. and Karan, A.K.(2009).' Reducing out-of-pocket expenditures to reduce poverty: a disaggregated analysis at rural-urban and state level in India', Health Policy and Planning;24:116-128.

Ghosh, S. (2011). Catastrophic Payments and Impoverishmentdue to Out-of-Pocket Health Spending. Economic \& Political Weekly.EPW. November 19, 2011, vol xlvi no 47.

http://www.indiaenvironmentportal.org.in/files/file/Out-of-Pocket\%20Health\%20Spending.pdf

Gupta, I. \& Chowdhury, S.(2014). Correlates of out-of-pocket spending on health in Nepal: implications for policy. WHO South-East Asia Journal of Public Health; July-December 2014, 3 (3-4).

Jack, W. (1999). Principles of health economics for developing countries. Washington DC: The World Bank.

Mahal A, Singh J, Afridi F et al.(2001). Who benefits from public health spending in India? New Delhi: National Council of Applied Economic Research.

Mahal A.(2003). The distribution of public health subsidy in India. In: Yazbeck AS, Peters DH (eds). Health policy research in South Asia: building capacity for reform. Human Development Network, Health, Nutrition and Population series. Washington DC: The World Bank, pp. 33-63, 2003.

Van Minh H, Kim Phuong N, Saksena P, James C, Xu, K. (2013). Financial burden of household out-of pocket health expenditure in Viet Nam: Findings from the National Living Standard Survey 2002-2010. Social Science \& Medicine, vol: 96 pp: 258-263

MoHP.(2010).Nepal Health Sector Programme- Implementation Plan II (NHSSP-IP 2) 2010 2015. Kathmandu: Ministry of Health and Population / Government of Nepal.

Thapa, A.K., Ghimire, N. \&Adhikari, SR.(2016). 'Access to Drugs and Out of Pocket Expenditure in Primary Health Facilities'.Journal of Nepal Health Research CouncilSepDec;14(34):139-42.

Thapa, A.K. \&Adhikari, S.R.(2016). 'Characteristics of Morbidity and Choice of Health Care Facilities in Nepal'. Journal of Advanced Academic Research (JAAR), July Vol. 2.No. II. RTI International.(2010).Health System Performance. Research Triangle Park, NC, USA. Van Doorslaer E, O. O’Donnell, R. P. Rannan-Eliya, A. Somanathan, S. R. Adhikari, C. C. Garg, D. Harbianto, A. N. Herrin, M. N. Huq, S. Ibragimova, A. Karan, C. W. Ng, B. R. Pande, R. Racelis, S. Tao, K. Tin, K. Tisayaticom, L. Trisnantoro, 
ISSN: 2362-1303 (Paper) | eISSN: 2362-1311 (Online)

C. Vasavid, and Y. Zhao (2006b). 'Effect of payments for health care on poverty estimates in 11 countries in Asia: an analysis of household survey data', Lancet 368: $1357-64$.

Wagstaff, A., \& Van Doorslaer, E. (1992). Equity in the finance of health care: some international comparisons. Journal of health economics, 11 (4), 361-387

Wagstaff, A., \& van Doorslaer, E. (2003). Catastrophe and impoverishment in paying for health care: with applications to Vietnam 1993-98. Health Economics, 12, 921-934.

Annex-1: ROC curve

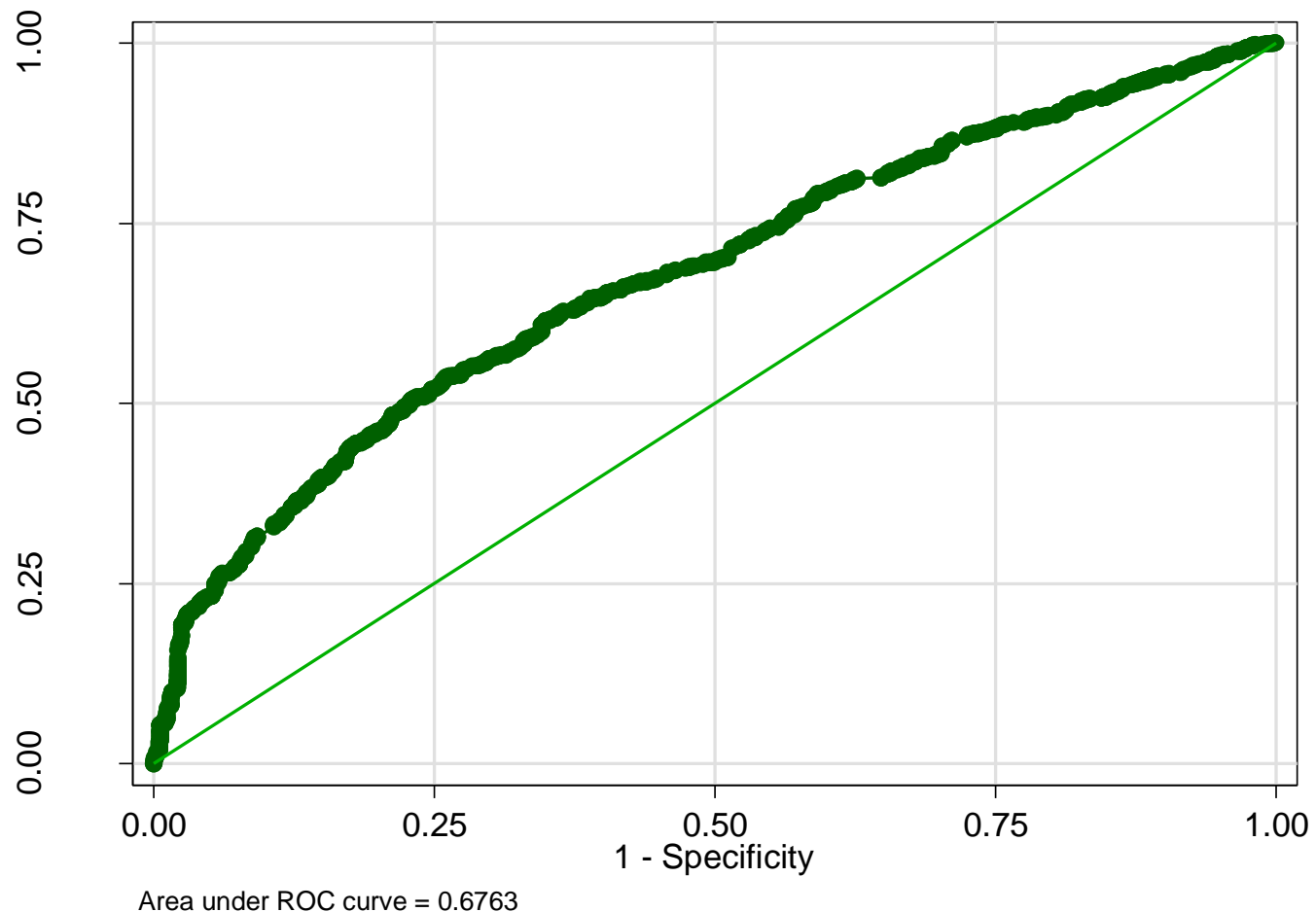

Area under ROC curve $=0.6763$ 